\title{
Effects of smoking habit and diagnosed COPD on intensive care unit stay length of surgically treated coronary artery and obstructive peripheral arterial disease patients
}

\author{
Ersin Çelik ${ }^{1}$ İsmail Yürekli ${ }^{1}$, Ufuk Yetkin ${ }^{1}$, Habib Çakir ${ }^{1 *}$, Köksal Dönmez $^{1}$, Metin Gümüş ${ }^{2}$, Rahika Durusoy ${ }^{2}$, \\ Ali Gürbüz'
}

From World Society of Cardiothoracic Surgeons 25th Anniversary Congress, Edinburgh

Edinburgh, UK. 19-22 September 2015

\section{Background/Introduction}

Smoking is one of the most important mortality and morbidity factors.

\section{Aims/Objectives}

We examined 868 coronary artery disease and 268 peripheral vascular disease patients who were treated surgically at our clinic between dates January 2007 and December 2010.

\section{Method}

Mean age of 868 coronary artery disease patients were $63,86 \pm 11,17$ (between 21-91 years) and 268 peripheral arterial disease patients were $65,44 \pm 10,37$ (between 2192 years).

\section{Results}

There were 47 COPD patients in 868 patients who underwent surgery for coronary artery disease. In addition, 490 patients were active smoker and 378 were not using tobacco products. Mean Intensive care unit stay for COPD patients was 4,81 day and 3,06 day for patients without COPD. This difference was significant $(\mathrm{p}<0.05)$.There were 31 COPD patients in 268 patients who underwent surgery for peripheral arterial disease. In this group, 172 patients were active smoker and 96 were not smoking. Mean Intensive care unit stay for
COPD patients was significantly longer in COPD group $(\mathrm{p}<0.05)$.

\section{Discussion/Conclusion}

We believe that, preoperative smoking cessation and long-term bronchodilator therapy will reduce morbidity rates of our patients in our daily practice.

\section{Consent}

Written informed consent was obtained from the patient for publication of this Case report and any accompanying images. A copy of the written consent is available for review by the Editor-in-Chief of this journal.

\section{Authors' details \\ 'Department of Cardiovascular Surgery, Katip Celebi University Izmir Ataturk Training and Research Hospital, Izmir, Turkey. ${ }^{2}$ Department of Public Health, Medical Sciences Faculty, Ege University, Bornova, 35040 Bornova/lizmir, Turkey.}

Published: 16 December 2015

doi:10.1186/1749-8090-10-S1-A227

Cite this article as: Celik et al.: Effects of smoking habit and diagnosed COPD on intensive care unit stay length of surgically treated coronary artery and obstructive peripheral arterial disease patients. Journal of Cardiothoracic Surgery 2015 10(Suppl 1):A227. 